\title{
A SEM Study Of the Electro-Reduction Of Strontium Ion On Cu Electrodes
}

\author{
Franco Cornacchiulo $^{1}$, Agustín Ávalos ${ }^{1}$, María d. 1. A. Cangiano ${ }^{2}$ and Marcelo R. Esquivel ${ }^{3,4^{*}}$ \\ 1. Instituto Sábato (UNSam - CNEA), San Martín, Buenos Aires Argentina. \\ 2. CONICET, INTEQUI and UNSL, Villa Mercedes, San Luis Argentina. \\ 3. CNEA, CONICET, Centro Atómico Bariloche, Bariloche, Rio Negro Argentina. \\ 4. UNCo-Bariloche, Bariloche, Río Negro Argentina \\ *Corresponding author: esquivel@cab.cnea.gov.ar.
}

The shale gas extraction via hydraulic fracture is a gas production method from non-traditional reservoirs [1]. The water management is, at least, a challenging issue because hydraulic fracture generates a large amount of wastewater containing different potentially toxic elements mixed in the waste. Among these, $\mathrm{Ba}$ and $\mathrm{Sr}$ ions are the most representative. Therefore, a valuable discussion should be done on the separation methods, analysis of risks and strategies for treatment. There is a large amount of different capture methods for these ions including adsorption in fixed structures and chemical reduction [1]. Among these techniques, the electro-reduction is a candidate to capture and separate soluble ions such as that of strontium [2]. The electro-reduction method is specially appropriated for use in mobile devices operated by remote control.

In this work, the reaction using $\mathrm{Cu}-\mathrm{Ni}$ electrodes is followed by using scanning electron microscopy (SEM) and associated techniques. The samples are observed in a FEI-INSPECT S50 microscope operated at $30 \mathrm{kV}$. The energy dispersive spectroscopy (EDS) measurements are done using an Octane Pro Detector (EDAX). To perform this work, SEM is a key technique because superficial study of the electrode is done to understand the kinetics of the capture of de divalent strontium ion. It is specially used to determine the morphology and the habit and form related to the geometric crystallography of the electrodes and the corresponding reaction products.

These characteristics are well described by SEM micro-images. The Figure 1.a shows a micro-image of the $\mathrm{Cu}$ cathode after the electro-reduction process for $30 \mathrm{~min}$ in a $0.1 \mathrm{M}$ strontium nitrate solution under a voltage of $24 \mathrm{~V}$. The cathodic reaction proceeds with strontium reduction and hydrogen evolution. The star shaped structure is Sr reduced on the surface. The bored sheet observed on the surface is $\mathrm{Cu}$ detached from the electrode. The remaining structure is the $\mathrm{Cu}$ cathode. The Figure $1 \mathrm{~b}$. shows a SEM micro image of the anode. The reaction leads to the formation of parallelepiped protuberances of the $F m 3 m$ space group. These structures relate to the sites where oxygen gas evolves during reaction. Notice the difference on this morphology and that of the cathode. The global process is exothermic and proceeds with change of the $\mathrm{pH}$ from 7 to 12 . The Figure 2 shows SEM micrographs. The Figure $2 \mathrm{a}$ shows the starting $\mathrm{Cu}$ electrode. Notice the former habit and forms of the Fm $3 m$ space group. The Figure 2 b shows the electrode after reaction. Notice the Sr reduced on the surface. The EDS measurements are done to verify the elemental composition of the structures. The results presented shows that $\mathrm{Sr}$ reduction proceeds along to both anodic oxygen evolution and cathodic hydrogen formation, respectively. It indicates that the process is kinetically and thermodynamically possible.

References:

[1] Y Sun et. al. Environm. Intern. 125 (2019), p 452.

[2] A. Vengosh et. al. Environ. Sci. Technol. 48 (2019), p. 8334. 


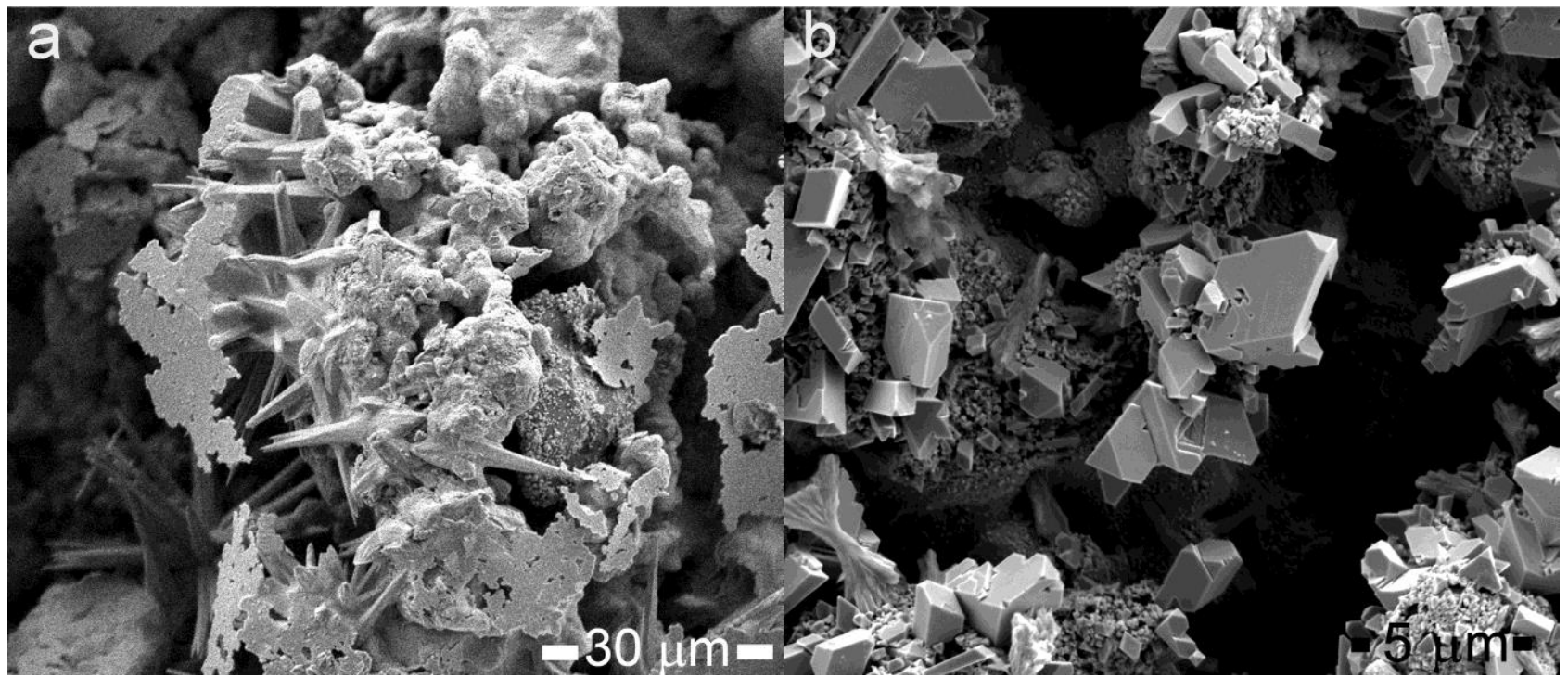

Figure 1. Scanning electron microscopy micrographs of the electrodes obtained in emissive mode after 5 min of reaction. $\mathbf{a}$. The $\mathrm{Cu}$ cathode. $\mathbf{b}$. The $\mathrm{Cu}$ anode.

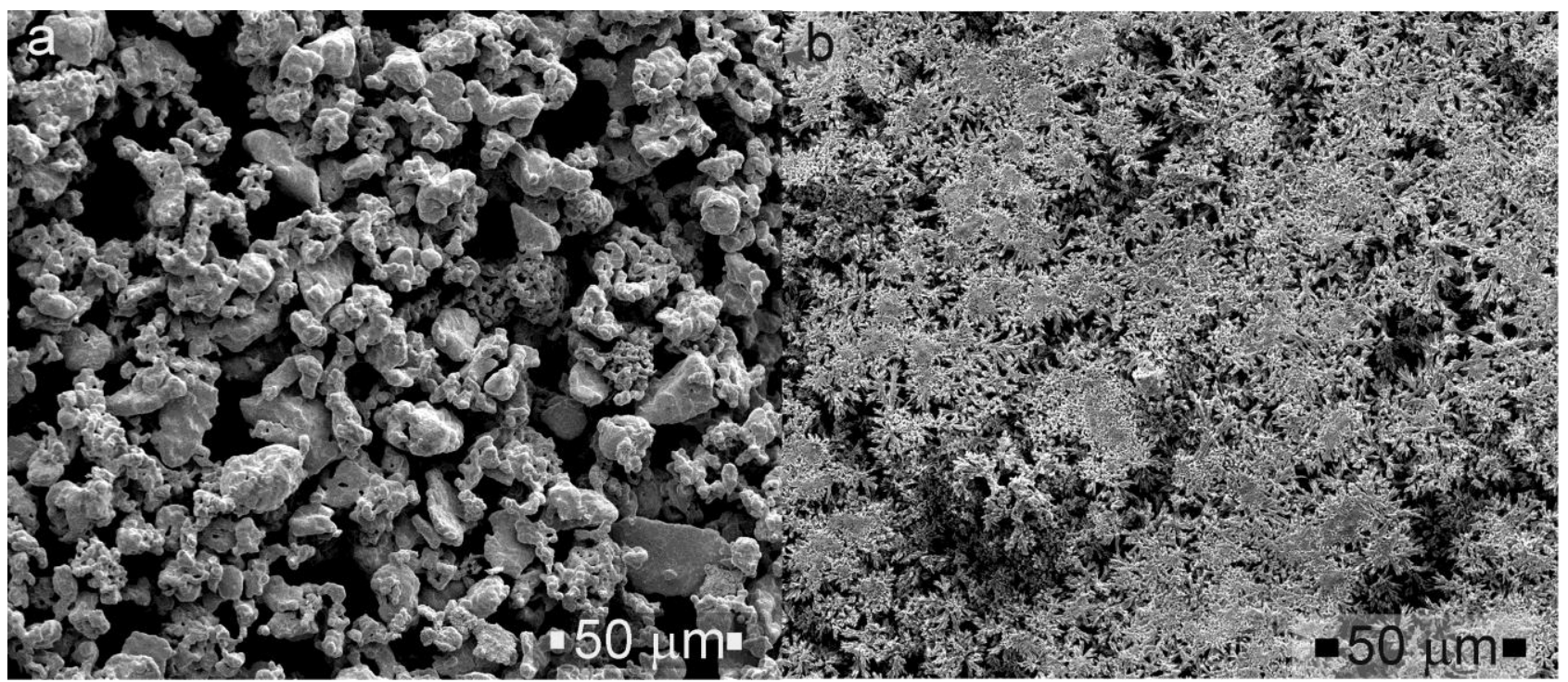

Figure 2. Scanning electron microscopy micrographs of the electrodes obtained in emissive mode. a. Starting $\mathrm{Cu}$ electrode. b. The same $\mathrm{Cu}$ electrode (cathode) after $30 \mathrm{~min}$ of reaction. 